\title{
A NOTE ON ANISOTROPIC POTENTIALS ASSOCIATED WITH THE LAPLACE-BESSEL DIFFERENTIAL OPERATOR
}

\author{
JAVANSHIR J. HASANOV
}

\begin{abstract}
In this note the anisotropic maximal operator and anisotropic Riesz potentials generated by the generalized shift operator are investigated in the anisotropic $B$-Morrey space $L_{p, \lambda, \gamma}\left(\mathbb{R}_{k,+}^{n}\right)$. We prove that the anisotropic $B$-maximal operator $M_{\gamma}$ is bounded on the anisotropic $B$-Morrey space $L_{p, \lambda, \gamma}\left(\mathbb{R}_{k,+}^{n}\right)$. Also the anisotropic $B$-Riesz potential $R_{\gamma}^{\alpha}$ is bounded from the anisotropic $B$-Morrey spaces $L_{p, \lambda, \gamma}\left(\mathbb{R}_{k,+}^{n}\right)$ to $L_{q, \lambda, \gamma}\left(\mathbb{R}_{k,+}^{n}\right)$ if and only if $1 / p-1 / q=\alpha /(|a|+(a, \gamma)-\lambda)$ and $1<p<(|a|+(a, \gamma)-\lambda) / \alpha$, and its modified version $\widetilde{R}_{\gamma}^{\alpha}$ is bounded from the anisotropic $B$-Morrey space to the anisotropic $B$-BMO space. Furthermore, we obtain some imbedding relations between the space $L_{p, \lambda, \gamma}\left(\mathbb{R}_{k,+}^{n}\right)$ and the anisotropic $B$-Stummel-Kato class $S_{p, \theta, \gamma}\left(\mathbb{R}_{k,+}^{n}\right)$.
\end{abstract}

Mathematics subject classification (2000): 42B20, 42B25, 42B35.

Keywords and phrases: Anisotropic $B$-maximal operator, anisotropic $B$-Riesz potential, anisotropic $B$-Morrey space, Sobolev-Morrey type estimates, anisotropic $B$-Stummel-Kato class.

\section{REFERENCES}

[1] D. R. ADAMS, A note on Riesz potentials, Duke Math., 42 (1975), 765-778.

[2] I. A. ALIEV AND A. D. GADJIEV, Weighted estimates for multidimensional singilar integrals generated by a generalized shift operator, (Russian) Mat. Sb. 183 English, translated (1992), no. 9, 45-66; translation from Russian Acad. Sci. Sb. Math. 77 (1994), no. 1, 37-55

[3] I. A. AlieV AND S. BAYRAKCI, On inversion of B -elliptic potentials by the method of Balakrishnan-Rubin, Fractional Calculus and Applied Analysis, 1 (1998), 4, 365-384

[4] O. V. BESOV, V. P. IL'IN AND S. M. NIKOL'SKII, Integral'nye predstavleniya funktsii i teoremy vlozheniya (Integral Representations of Functions and Embedding Theorems), Moscow: Nauka, 1975.

[5] R. R. COIFMAN AND G. WEISS, Analyse harmonique non commutative sur certains espaces homogenes, Lecture Notes in Math., 242, Springer-Verlag, Berlin, 1971.

[6] F. ChIARENZA AND M. FRASCA, Morrey spaces and Hardy-Littlewood maximal function, Rend. Math., 7 (1987), 273-279.

[7] D. DANIELLI, A Fefferman-Phong Type Inequality and Applications to Quasilinear Subelliptic Equatioins, Potential Analysis, 11 (1999), 387-413.

[8] A. D. GADJIEV AND I. A. ALIEV, On classes of operators of potential types, generated by a generalized shift, Reports of enlarged Session of the Seminars of I. N. Vekua Inst. of Applied Mathematics, Tbilisi. (1988) 3, 2, 21-24 (Russian).

[9] D. D. Gasanov, V. S. GuliYev, Some properties of anisotrop Riesz-Bessel-Fourier potentials, Vestnik Russian Peoples Friendship University, 6(1999), 1, 63-82.

[10] V. S. GuLIEv, Sobolev theorems for the Riesz B-potentials, Dokl. RAN, 358 (1998), 4, 450-451. (Russian)

[11] V. S. GULIEv, Some properties of the anisotropic Riesz-Bessel potential, Analysis Mathematica, 26 (2000), 2, 99-118. 
[12] V. S. GuLIEV, On maximal function and fractional integral, associated with the Bessel differential operator, Mathematical Inequalities and Applications, 6 (2003), 2, 317-330.

[13] V. S. GULIYEV AND J. J. HASANOV, Sobolev-Morrey type inequality for Riesz potentials, associated with the Laplace-Bessel differential operator, Fractional Calculus and Applied Analysis. 9 (2006), 1, 17-32.

[14] V. S. GULIYEV AND J. J. HASANOV, Necessary and sufficient conditions for the boundedness of Riesz potential associated with the Laplace-Bessel differential operator in Morrey spaces, J. Math. Anal. Appl. 347 (2008) 113-122.

[15] B. M. LEVITAN, Bessel function expansions in series and Fourier integrals, Uspekhi Mat. Nauk 6 (1951), 2(42), 102-143. (Russian)

[16] L. N. LYAKHOV, On a class of spherical functions and singular pseudodifferential operators, Dokl. Akad. Nauk. 272(1983), 4, 781-784; English translation: in Soviet Math. Dokl. 28 (1983), 2, 431-434.

[17] I. A. KIPRIYANOv, Singular elliptic boundary value problems. M. Nauka, Physmathlit, 1997, p. 208, (Russian)

[18] I. A. KIPRIYANOV AND M. I. KLYUCHANTSEV, On singular integrals generated by the generalized shift operator II, Sibirsk. Mat. Zh., 11(1970), 1060-1083; translation in Siberian Math. J., 11(1970), 787-804.

[19] C. B. MORREY, On the solutions of quasi-linear elliptic partial differential equations, Trans. Amer. Math. Soc. 43 (1938), 126-166.

[20] B. MuCKENHOUPT AND E. M. STEIN, Classical expansions and their relation to conjugate harmonic functions, Trans. Amer. Math. Soc., 118(1965), 17-92.

[21] M. A. Ragusa AND P. ZAMBONI, A potential theoretic inequality, Czechoslovak Mathematical Journal, 51 (2001), 126, 55-65.

[22] M. SCHECHTER, Spectra of Partial Differential Operators, North Holland, 1986.

[23] A. SERBETCI AND I. EKINCIOGLU, On weighted estimates of high order Riesz-Bessel transformations generated by the generalized shift operator, Acta Mathematica Sinica, 21, 1, 53-64 (2005).

[24] K. STEMPAK, Almost everywhere summability of Laguerre series, Studia Math. 100 (2)(1991), 129-147.

[25] K. TRIMECHE, Inversion of the Lions transmutation operators using generalized wavelets, Applied and Computational Harmonic Analysis, 4 (1997), 97-112. 